\title{
CENTRO SAPIENS: ECONOMIA CRIATIVA APLICADA NO CENTRO HISTÓRICO LESTE DE FLORIANÓPOLIS.
}

\section{SAPIENS CENTER: CREATIVE ECONOMY APPLIED IN THE EAST HISTORICAL CENTER OF FLORIANOPOLIS.}

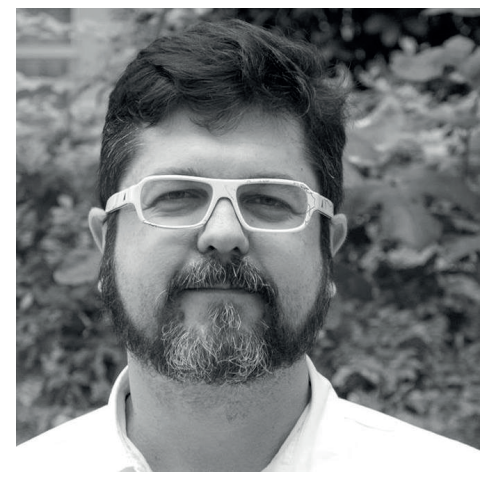

\section{Luiz Salomão Ribas Gomez}

Pós-doutorando (Saxion University of Applied Sciences) Professor Associado (Universidade Federal de Santa Catarina).

Coordenador do Centro Sapiens. salomao@centrosapiens.com.br

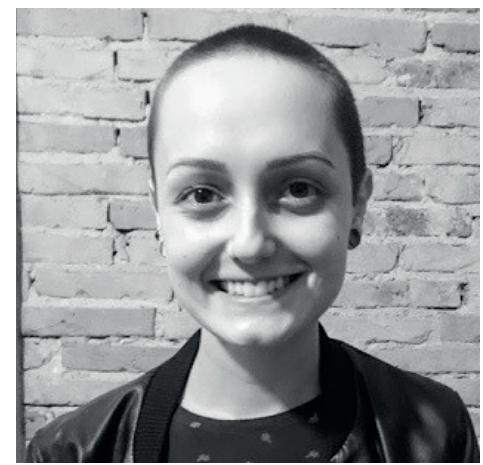

\section{Daniele Diniz Warken}

Especialista UX Design (Universidade Federal de Santa Catarina).

Gestora do Centro Sapiens.

contato@centrosapiens.com.br

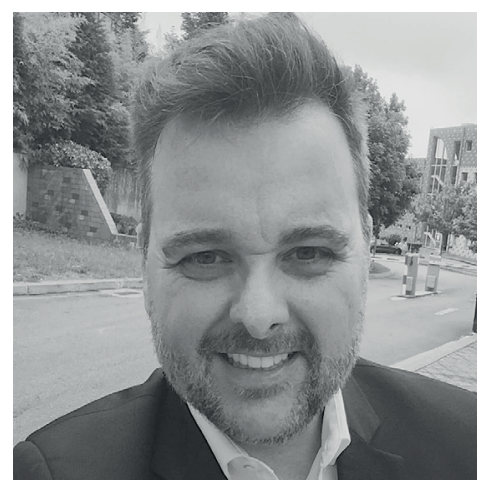

\section{Renato Buchele Rodrigues}

Doutorando em Turismo (Universidade do Vale do Itajai). Diretor do Centro de Ciências Sociais Aplicadas Universidade do Vale do Itajaí. renatobr@univali.br 


\section{RESUMO}

Neste artigo apresentamos o processo de implantação do Distrito Criativo Centro Sapiens, projeto de revitalização e revisitação urbano do Centro Histórico Leste de Florianópolis por meio da construção de um polo de Economia Criativa, criado pelo Laboratório de Orientação da Gênese Organizacional (LOGO|UFSC) e desenvolvido por ele com apoio do Sapiens Parque, do Laboratório VIA e por um rol de apoiadores que fazem parte do Conselho Gestor do empreendimento. São apresentados os conceitos de Economia e Cidade Criativa que fundamentam o projeto e o benchmarking que foi utilizado para validar as ideias que foram trazidas da teoria. Por fim, se apresenta o projeto, sua implantação, suas primeiras ações e os resultados alcançados nos dois primeiros anos.

\section{PALAVRA-CHAVE}

Economia Criativa; Cidade Criativa; Centro Sapiens; Florianópolis.

\section{ABSTRACT}

In this paper we present the Sapiens Center Creative District implementation process, a revitalization and urban renewal project of the East Historical Center of Florianopolis through the construction of a Creative Economy pole created by the Laboratory for the Orientation of the Organizational Genesis (LOGO | UFSC) and developed by it with the support of Sapiens Park, VIA Laboratory and a group of supporters who are part of the Management Council of the action. We present the concepts of Economic and Creative City that support the project and the benchmarking that was used to validate the ideas that were brought from the theory. Finally, it presents the project, its implementation, its first actions and the results achieved in the first two years.

\section{KEYWORDS}

Creative Economy; Creative City; Sapiens Center; Florianópolis.

\section{INTRODUÇÃO}

Já quase no final do Século XX, em 1996, Michel Maffesoli apresenta em seu livro "O tempo das tribos", onde ele filosofa sobre a mudança na sociedade individualista e sugere que a sociedade de massa é o que move a economia da época. Em contraponto, Lipovetsky, já no século XXI, ancorado nas ideias de Richard Dawkins sobre o Gene Egoísta, sugere uma sociedade hiperindividualista onde cada consumidor busca a própria felicidade mesmo nos momentos quando age 
de forma altruísta. Lipovetsky (2007) sugere uma sociedade nova onde todos estão preocupados com o "seu" telefone, o "seu" carro ou mesmo em ser líder da "sua" tribo (mesmo quando ela é uma tribo de um único elemento: ele mesmo). Porém, o próprio Lipovetsky coloca que o mundo precisa de ética para se manter existindo, o que nos sugere que o que ele prega pode se completar com o que Maffesoli apresenta, e vice-versa, dentro da proposta da nova revolução industrial, muito bem apresentada no modelo de sociedade com custo marginal zero de Rifkin (2015), onde estamos vivendo uma quarta revolução industrial onde nem o capitalismo, nem o socialismo, nem o liberalismo e nenhuma outra forma conhecida de sistema conseguirá se sustentar dentro de novas regras dessa nova economia, denominada criativa, onde a propriedade não será mais exclusiva de "alguém" e sim disponível para todos a custos muito próximos do zero. Pode-se voltar bastante no tempo, lá em 1950, quando A.E. van Vogt escreve Voyage of the Space Beagle, que no Brasil recebeu o nome de Missão Interplanetária, e lança o termo nexialismo para o mundo. Nexialismo é uma supraciência que consegue integrar várias ciências e várias expertises próximas a situações generalistas, que felizmente não é conseguido por uma única pessoa e sim por um grupo de pessoas trabalhando, agora num termo mais atual, de forma colaborativa. Longo e Tavares (2010) trazem o conceito de nexo para o mercado, o que se adequa muito bem às novas iniciativas que vêm surgindo na nova economia que vivemos, onde maker spaces, coworkings, FabLabs e outras iniciativas, convergem as pessoas para um novo modelo de negócio focado na criatividade e no nexialismo.

Essa nova perspectiva ultrapassa os limites das empresas ou das escolas e se expande para as cidades quando surge o conceito de smart city ou como é chamado no Brasil: cidade inteligente. Traduzir smart city por cidade inteligente talvez não seja a forma mais ampla de tratar o tema que tem discutido como o da criatividade sendo o motor de desenvolvimento das cidades como Florida (2002, 2004,2005 e 2011) trata em suas teorias para o assunto. Florida (2002) define que uma Cidade Criativa tem sua capacidade criativa concentrada em 3 Ts: "Talento, Tolerância e Tecnologia". O que nos leva a retornar aos conceitos de nexialismo e hiperindividualismo. Para termos cidades criativas e, por conseguinte, uma indústria criativa implantada alterando a sua economia para o foco na criatividade, não podemos mais pensar individualmente e sim focar o uso de toda a tecnologia disponível para que os talentos individuais colaborem entre si, sem preconceitos, construindo um lugar melhor para se viver em todos seus aspectos.

Este artigo, por meio de um levantamento teórico e sob a percepção dos au- 
tores em visitas técnicas à cidades e regiões mais adiantadas no processo de implantação das atividades de economia criativa em prol da sociedade, apresenta o estudo de caso aplicado Distrito Criativo Centro Sapiens, na cidade de Florianópolis, focando já na atividade e nos resultados do Cocreation Lab, que está em funcionamento desde o início de 2016.

\section{ECONOMIA CRIATIVA}

O conceito de economia criativa começou a ser estabelecido na década de 1990 a partir de uma ação do governo australiano denominada "creativenation" que trazia uma nova proposta para o desenvolvimento econômico, quando a cultura se tornaria um campo para investimentos públicos e foi destacado pela globalização, o surgimento de novas mídias e o conhecimento valorizado enquanto ativo (Reis, 2011). Com a multiplicação das multinacionais, mobilidade de recursos e de ativos financeiros, surgimento de novos mercados e acesso instantâneo à informação, incutiu-se na sociedade uma nova busca por valores intangíveis e ressignificação de identidades. Desta forma o capital humano e criativo tornou-se o principal ativo na produção de bens e serviços com diferencial competitivo e valor agregado. $O$ consumidor passa a ter como fator decisório a emoção, a estética e a experiência.

Uma das primeiras organizações a sistematizar a ideia de uma economia criativa foi o governo do Reino Unido em 1998 através do documento "Mapeamento das indústrias criativas" (BOP Consulting, 2010), apresentado pelo DCMS - Departamento de Cultura, Mídia e Esporte. O conceito de indústrias criativas é colocado como "atividades que têm sua origem na criatividade, habilidade e talento individuais, assim como possuem o potencial de criar emprego e riqueza através da geração e exploração da propriedade intelectual" (DCMS, 1998 apud BOP Consulting, 2010). O governo do Reino Unido criou então um grupo de trabalho misto, com instituições públicas e privadas, que viabilizaram o estudo e coleta de dados sobre as indústrias criativas, que revelou representarem $4 \%$ do PIB da Grã-Bretanha e estarem transformando o seu ambiente econômico. Em um momento de recessão que o Brasil passa, o PIB da indústria criativa brasileira chegou a $\mathrm{R} \$$ 155,6 bilhões no fim de 2015 (valor equivalente à soma dos valores de mercado das marcas Facebook, Zara e L'Oréal), ou o equivalente, como mostra o Gráfico 1 a 2,64\% do total produzido no país naquele ano (FIRJAN, 2016)1.

1 SISTEMA FIRJAN • MAPEAMENTO da INDÚSTRIA CRIATIVA NO BRASIL • 2016 


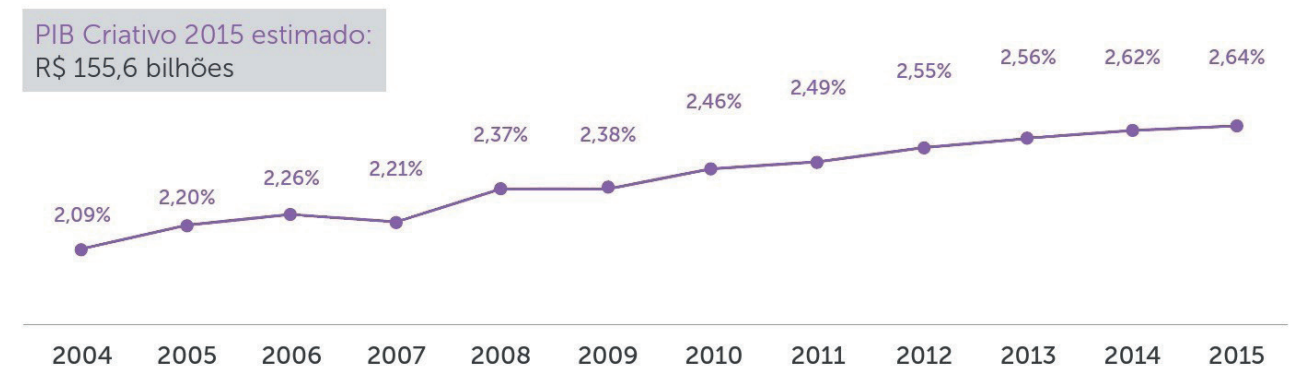

Gráfico 1: Crescimento do PIB Economia Criativa no Brasil .

Fonte: FIRJAN, 2016

"À medida que a economia se desenvolve, o padrão de vida melhora, as pessoas ficam menos apegadas a grandes instituições, se tornam mais abertas e adquirem um ponto de vista mais tolerante no que se refere aos relacionamentos pessoais" (FLORIDA, 2011).

Assim, muitas das pessoas criativas, que em grande parte crescem sentindo-se excluídas e diferentes da maioria das pessoas que as cercam, encontram um ambiente aberto às diferenças, ao qual podem "pertencer" (TARACHUKY, 2015), criando o conceito dos maker spaces que dominam as chamadas cidades criativas. Florida (2011), considera que "o crescimento econômico regional é promovido pelas escolhas geográficas dos indivíduos criativos - os detentores do capital criativo - que preferem lugares diversificados, tolerantes e abertos a novas ideias". Logo, os criativos utilizam uma série de fatores na hora de decidir onde trabalhar e viver, mas principalmente demonstram um afastamento das comunidades empresariais tradicionais e se dirigem a lugares denominados como centros criativos. Centros criativos são regiões com alta concentração de resultados econômicos sob a forma de inovações e crescimento do setor de alta tecnologia, além da elevada concentração de integrantes da classe criativa. Em geral os fatores atrativos para a classe criativa, incluem diversidade cultural, ambiente acolhedor e amigável, comunidade com mente aberta, qualidade de vida, estilo de vida, envolvimento em questões sociais, habitação, densidade e forma urbana, segurança, espaços verdes, recursos naturais, transporte público, limpeza, tempo e localização (TREMBLAY; DARCHEN, 2010). Com isso corrobora Asheim e Hansen (2009), que também considera que a classe criativa é atraída por lugares que oferecem diversidade cultural e espaço para a individualidade, os quais podem promover uma economia inovadora e abertura para migrantes e imigrantes. Qian (2010), inclusive, ressalta que quanto mais diversificada for 
a população de uma região mais amplo será o leque de conhecimentos disponíveis e maior será a possibilidade de combinar conhecimento existente para gerar inovação.

Esse movimento tem se tornado uma realidade constante em cidades que buscam melhorar o padrão de vida de seus habitantes. Principalmente aquelas que cresceram além da expectativa, trazendo muitas pessoas de outros lugares para preencher as suas necessidades econômicas. Essa mudança da entrada de novos habitantes faz, muitas vezes, que essas cidades percam um pouco (às vezes muito) de sua identidade e história. Essas cidades precisam então recuperar o que perderam e fazem isso tentando integrar "nativos" e "forasteiros" pela história, pela cultura, pela tecnologia e pela aproximação social entre eles, se construindo como cidades criativas.

\section{CIDADES CRIATIVAS}

Talvez o conceito de "cidade criativa" atualmente mais aceito é atribuído a Bianchini e Landry (1995), que Landry (2000) aperfeiçoa, utilizando a criatividade no seu sentido mais amplo, definindo como o "out of box" pode contribuir para que as cidades encontrem uma forma mais fácil de resolver seus problemas. Ele avalia que qualquer que seja a forma de criatividade aplicada na cidade irá fazer diferença positiva para ela. Não importa que seja no viés técnico, acadêmico, científico, cultural ou artístico, apenas ela precisa ser desenvolvida e aplicada de forma multidisciplinar e colaborativa (TARATCHUKY, 2015). As cidades precisam aplicar fortemente o conceito de nexialismo para serem consideras inteligentes e criativas (smart cities).

Sugere-se que na Cidade Criativa sempre há mais potencial criativo em algum lugar, nunca faltando oportunidade para se inovar. Landry (2000) coloca que devem ser criadas condições para que se possa tornar as cidades mais habitáveis, aproveitando a imaginação e o talento das pessoas para reinventar a sua própria cidade como, por exemplo, um centro de criatividade, que possa unir as pessoas para potencializar e melhorar a qualidade de suas próprias vidas. As Cidades Criativas facilitam o surgimento de novas formas de interação entre as pessoas, de modo que estas encontrem as mais inovadoras soluções pensando em onde e como elas mesmas vivem, melhorando seu próprio espaço urbano. Uma cidade criativa consegue conviver, por algum tempo, em um ambiente caórdico (HOOCK, 2009), enquanto busca as soluções para se reinventar e construir os "padrões" ou "não padrões" que buscará seguir com seus habitantes. 
"Essas cidades são autênticas em sua identidade, atraem pessoas de outras regiões e mantêm sua história viva na paisagem e na memória. São lugares onde trabalhar, morar e se divertir são atividades associadas, onde as coisas acontecem e se transformam de maneira dinâmica (REIS, 2011) a partir das interações entre os diferentes agentes presentes nela." (TARACHUKY, 2015)

Lorentzen (2009), fortalece a importância dos moradores e dos visitantes pois eles ajudam a tornar a cidade mais ou menos interessante e acolhedora, construindo a experiência que ela ajuda a proporcionar.

Graças ao avanço global das políticas de valorização das experiências culturais e criativas feitas pelas cidades em 2004, a UNESCO estabeleceu uma Rede de Cidades Criativas, com o intuito de desenvolver a cooperação internacional entre as cidades que identificaram a criatividade como um fator estratégico de desenvolvimento sustentável e obter uma aliança global para o estímulo da diversidade cultural através da troca de experiências, know-how, capacidades de negócio e tecnologia. As cidades participantes podem se enquadrar em sete categorias: literatura, cinema, música, artesanato e arte regional, artes midiáticas, design e gastronomia. No Brasil, a Secretaria de Economia Criativa do Ministério da Cultura, criada pelo Decreto 7743 de $1^{\circ}$ de junho de 2012, e atualmente nomeada Secretaria de Economia da Cultura, desde então vem apresentando estudos de prospecção e avaliação de Polos Criativos no país, resultantes de consultoria da UNESCO.

Para realização desta pesquisa com vistas à implantação de um distrito criativo na cidade de Florianópolis os pesquisadores fizeram um levantamento técnico de lugares ou cidades que já eram reconhecidas por suas práticas de viabilização de ações da economia criativa e também se assemelhavam com Florianópolis em estrutura social, demográfica e econômica. Nessa pesquisa foi observada uma aproximação não só da cidade de Florianópolis, mas também do estado de Santa Catarina com a região da Catalunha na Espanha e mais especificamente com o projeto 22@Barcelona, observou-se também uma semelhança com a com os projetos de Recife do Porto Digital e do Distrito Criativo Ruta N em Medellin, na Colômbia. Porém, encontrou-se uma semelhança sinérgica com o projeto do Urban Center de Bolonha na Itália.

Usamos essas referências para a fundamentação do projeto e para entender mais das capacidades, competências e ações realizadas pelas cidades criativas optou-se por visitar oficialmente o projeto de Bolonha (outubro 2014) por ser uma cidade criativa oficial da UNESCO e também ter semelhanças muito fortes 
na formatação populacional e no lançamento de um projeto de branding turístico como se pretende implantar em Florianópolis.

\subsection{BARCELONA, RECIFE E MEDELLIN}

Ações de revitalização de espaços urbanos atrelados ao desenvolvimento da tecnologia, inovação e criatividade foram fundamentais e se enquadram como cases de sucesso em diversas cidades do mundo. Entre o exemplo mais memorável está a cidade de Barcelona. A capital catalã, nomeada como Capital Europeia da Inovação em 2014, conquistou este título por meio do emprego de uma política cultural de promoção ao diálogo e mais participação cidadã, além do redesenvolvimento de espaços industriais obsoletos, como o Poblenou, transformado no $22{ }^{\circ}$, um distrito empresarial que funciona como laboratório urbano.

O Porto Digital é um dos principais parques tecnológicos e ambientes de inovação do Brasil e é um dos representantes da nova economia do Estado de Pernambuco. Reconhecido por sua territorialidade singular entre parques tecnológicos, o Porto Digital é um parque urbano instalado no centro histórico do Bairro do Recife e no bairro de Santo Amaro, totalizando uma área de 149 hectares. A região, antes degradada e de pouca importância para a economia local, vem sendo requalificada de forma acelerada em termos urbanísticos, imobiliários e de recuperação do patrimônio histórico edificado desde a fundação do parque, em 2000. Desde a fundação do Porto Digital, já foram mais de 50 mil metros quadrados de imóveis históricos restaurados em toda a extensão territorial do parque tecnológico².

Na Colômbia, Medellín alcançou o título mundial de Cidade do Ano em 2013 após um processo de revitalização e inclusão social que teve início há quase vinte anos. A cidade, que já foi considerada uma das mais violentas do mundo, com altas taxas de criminalidade e intensa atividade de tráfico de drogas, apostou em políticas públicas com foco em programas de educação, empreendedorismo e inovação e na inserção da população nos processos culturais, econômicos e sociais. O resultado foi a revitalização de áreas excluídas com a apropriação de espaços públicos por meio de projetos de arquitetura e design, o que criou pontos de atração e a implementação de instituições que promovem o desenvolvimento de negócios inovadores de base tecnológica, como a Ruta N.

2 www.portodigital.org/parque/o-que-e-o-porto-digital 


\subsection{BOLONHA}

A ideia de se implantar uma proposta de identidade própria para Florianópolis e um projeto de fortalecimento das atividades da economia criativa na cidade nos levou a conhecer o projeto do Urban Center Bologna, na Itália. Foi feita uma visita técnica e realizada uma reunião como Professor Roberto Grandi e com os demais coordenadores do projeto em Outubro de 2014, quando foi nos

apresentado toda a proposta, deixando mais claro ainda as semelhanças entre as duas cidades e as duas propostas (GRANDI, 2015).

O Urban Center Bologna ${ }^{3}$ foi criado em 2005, e além de centralizar os projetos e grupos de trabalho de transformação urbana e territorial, também concentra atividades culturais. A cidade ainda faz parte desde 2006 da rede de cidades criativas da UNESCO no campo da Música e tem organizado diversos eventos para promover a internacionalização da música bolonhesa e também o turismo a partir da música.

Bolonha é a cidade da primeira universidade do mundo. É uma cidade de muitos apelidos, como "a aprendiz" ou "a gorda", dada a sua reputação de gastronomia e "a vermelha", primeiro a se referir à cor dos seus telhados e, em seguida, aos governos de sua esquerda que dão um sentido ao lugar. Bolonha não é uma cidade grande mesmo para os padrões europeus, tem cerca de 390.000 habitantes e desses $25 \%$ são estudantes, o que tem moldado a personalidade da cidade como um centro de conhecimento e pesquisa.

O formato da industrialização de Bolonha com estrutura em forma de redes especializadas e flexíveis tornou seu setor de manufatura muito avançado. Atualmente muitas outras cidades procuram imitar este modelo de sucesso e de resultado em diferentes cadeias como alimentos, moda, tecnologia, veículos.

Faz sentido que Bolonha seja considerado um dos lugares mais criativos da Europa. A cidade tem uma das menores taxas de desemprego e uma das maiores taxas de renda per capita na Europa. Foi conhecido pelo tempo como um dos lugares mais dinâmicos e bem geridos da Itália. Existe uma economia social forte, bem documentada, e uma participação cidadã ativa que ajuda a gerenciar e oferecer serviços sociais, de saúde e educacionais.

Graças a grande população estudantil, Bolonha não tinha preocupação em movimentos turísticos-culturais, pois os estudantes davam conta de incentivar e manter os aspectos culturais da cidade. Sendo assim, ela ficou muito mais re conhecida como uma cidade comercial/industrial. Seu foco de política cultural 3 www.urbancenterbologna.it 
tem sido tradicionalmente mais focado na produção do que no consumo através de espetáculos e eventos.

A grande mudança ocorreu no ano de 2000 quando Bolonha foi ele a Cidade Europeia da Cultura ${ }^{4}$. Muitos novos projetos surgiram, como o já citado Urban Center em 2005 e, mais recentemente, em 2010, o Bologna's Creative Innovation (Incredibol ${ }^{5}$ ), que é um programa de inovação criativa realizado por uma parceria público-privada e de terceiro setor comprometida em "adotar" a melhor criatividade local Empresas, oferecendo-lhes instalações, finanças, consultoria, consultoria e oportunidades de trabalho.

Quando você já é relativamente bem-sucedido e tem uma história e pessoas preparadas para atuar, há muitas vezes menos esforço para empurrar seu perfil criativo de forma tão vigorosa. Assim Bolonha se aproxima muito do perfil de Florianópolis, trazendo-lhe muitas ideias para serem implantadas.

\subsection{FLORIANÓPOLIS}

Florianópolis, capital do Estado de Santa Catarina, possui uma parte insular (Ilha de Santa (atarina) e outra parte continental, incorporada à cidade em 1927. As duas porções são ligadas pelas pontes Colombo Salles e Pedro Ivo Campos por onde trafegam os veículos - e a ponte Hercílio Luz, a maior ponte pênsil do Brasil, tombada como Patrimônio Histórico e Artístico. Atualmente, a capital catarinense possui cerca de 400 mil habitantes que vivem ao longo da ilha e em sua porção continental.

As lendas, mitos e histórias de bruxas criaram em Florianópolis uma cultura especialmente rica que aliada ao seu desenvolvimento tecnológico gera um cenário propício à promoção de iniciativas criativas e inovadoras, como é o caso da economia criativa. Qualidade de vida, atração de talento profissional, trocas sociais e culturais, características naturais e ambiente colaborativo demonstram que a capital catarinense é uma cidade criativa.

Assim como Bolonha, Florianópolis é uma cidade fortemente acadêmica, sendo que a Universidade Federal de Santa Catarina sempre aparece entre as 10 meIhores universidades do país. $O$ ensino em Florianópolis é um setor muito forte da economia que abriga mais de uma dezena de universidades públicas e privadas, ensino fundamental e médio de referência, além de dezenas de centros de pesquisa. Atualmente a cidade tem aproximadamente 80.000 estudantes, o

\footnotetext{
4 Forum d'Avignon, 2011- Creativity, Culture \& the City: A question of interconnection by Charles Landry

$5 \quad$ www.incredibol.net
} 
que equivale a $20 \%$ de sua população.

O setor tecnológico em Florianópolis se deu pela combinação de uma política de desenvolvimento iniciada na década de 80 e a produção de conhecimento pelas instituições e centros de pesquisa de excelência ali instalados. Essa vocação da cidade foi reconhecida em diversos rankings e pesquisas. Entre eles, o estudo da Delta Economics \& Finance $2015^{6}$ que coloca Florianópolis como referência nacional de ambiente de negócios, propícia para receber cada vez mais empresas de alto crescimento no futuro. Já o levantamento Melhores Cidades do Brasil ${ }^{7}$, da publicação Istoé e a consultoria Austin Rating, apontou a cidade como vencedora na categoria Indicadores Digitais, além de ser líder nos quesitos acesso ao conhecimento e mobilidade digital. A capital também foi considerada, em 2017, a sexta cidade mais inteligentes do país pelo Ranking Smart Cities ${ }^{8}$. Junto à tecnologia, a Ilha de Santa Catarina é também reconhecida internacionalmente pelo seu turismo e suas belezas naturais.

Florianópolis também é a primeira cidade brasileira a fazer parte da Rede Mundial de Cidades Criativas da UNESCO na categoria gastronomia. Sua inclusão na Rede, apoiada por cidades de países como Suécia, Colômbia e China, prevê diversas iniciativas ligadas à gastronomia, entre elas, a produção de um festival internacional anual; workshops com especialistas sobre cooperação criativa ligando design, artesanato, gastronomia e turismo; a criação de um Observatório Nacional da Gastronomia e a criação do Núcleo de Inovação Cultural para gerar um espaço de compartilhamento de experiências e conhecimentos com foco na Economia Criativa, especialmente em relação à gastronomia.

No que diz respeito a ambientes de inovação o ecossistema de Florianópolis e muito rico e pode-se dar destaque ao Sapiens Parque, que é um parque de inovação que reúne ciência, arte e meio ambiente em um único espaço com o objetivo de gerar iniciativas e experiências de sucesso, sendo o maior parque de inovação da América Latina. É um parque de inovação em um ambiente que possui infraestrutura e dedica seu espaço para abrigar empreendimentos $\mathrm{e}$ outras iniciativas inovadoras estratégicas para o desenvolvimento de Florianópolis. O grande diferencial do Sapiens é possuir um modelo para atrair, desenvolver, implementar e integrar as iniciativas com o objetivo de estabelecer um posicionamento diferenciado, sustentável e competitivo.

Porém, o Sapiens Parque está instalado no extremo norte da ilha, distante mais

$6 \quad$ www.deltaef.com

7 www.melhorescidadesdobrasil.com.br

8 www.exame.abril.com.br/brasil/as-100-cidades-mais-inteligentes-e-conectadas-do-brasil 
de 20 quilômetros do centro de Florianópolis, das Universidades e das atividades culturais que ocorrem fortemente na ilha. Essa distância atrapalha o Parque em conseguir se tornar um ambiente amigável e frequentado pelos jovens empreendedores da economia criativa. Estar mais próximo desses empreendedores e de onde eles frequentam se fazia imprescindível para a integração conceitual/emocional do Sapiens Parque ao ecossistema de inovação da cidade.

\section{CENTRO SAPIENS}

O Distrito Criativo Centro Sapiens é um projeto de desenvolvimento tecnológico territorial voltado à promoção do setor da Economia Criativa, principalmente o turismo, gastronomia, artes, design e tecnologia. A iniciativa, vinculada ao Sapiens Parque e à Prefeitura Municipal, atua no centro de Florianópolis, complementando projetos correlatos de instituições parceiras.

Em meados de 2014, inicialmente com a intenção de aproximar o Sapiens Parque e as temáticas de Inovação e Empreendedorismo da comunidade de Florianópolis, o bairro do Centro, em especial a porção leste histórica, começou a chamar atenção para a possibilidade de receber espaços de estímulo, apoio e discussão da criatividade. Em sintonia com algumas iniciativas que já surgiam e visavam a movimentação e ocupação desta área com atividades culturais, como a Feira Viva a Cidade9, além de projetos públicos para melhorias na infraestrutura, o projeto Centro Sapiens começou a ser estruturado. Foram mapeadas algumas ruas e quadras com maior necessidade de requalificação urbanística e número de prédios degradados ou abandonados.

Essa articulação começou a partir do Sapiens Parque com parceria do LOGO - Laboratório de Orientação da Gênese Organizacional - laboratório da UFSC voltado para atividades de pesquisa, ensino e extensão especialmente nas áreas de Branding, Inovação e Design. O LOGO/UFSC desde 2009 tem sido agente fomentador de projetos de desenvolvimento territorial da cidade de Florianópolis, em grande parte no viés tecnológico e turístico, contribuindo de ações relativas às marcas de startups até ações cocriativas com a comunidade em projetos como Rota da Inovação, Floripa Inteligente e Minha Floripa. O laboratório coordena diretamente o projeto Centro Sapiens, interligando os diversos atores do desenvolvimento urbano, empreendedorismo, comércio e da economia criativa em um comitê gestor, e organizando os planos de ações para a área. Sobrepujando esse viés, o Sapiens Parque, idealizador e financiador do projeto,

9 Ação da CDL de Florianópolis. www.cdlflorianopolis.org.br/conteudo/viva-a-cidade-127 
vem se estruturando desde 2001 sobre quatro clusters base: Tecnologia, Turismo, Serviços e setor Público. Dentro dessas áreas a economia criativa se estabelece como fundamental, tendo em vista, como já citado, a nova sociedade e seu potencial intelectual, a vocação de Florianópolis para o setor tecnológico, e o papel crucial da cultura para o desenvolvimento da cidade. Sendo assim, visando fortalecer Florianópolis como um polo de inovação e dinamizar e revitalizar o centro histórico da cidade, especialmente o setor leste, por meio de ações relacionadas à Economia Criativa, a área delimitada pelo projeto foi nomeada Distrito Criativo Centro Sapiens. O Distrito Criativo Centro Sapiens abrange a porção entre o Palácio Cruz e Sousa (Rua Trajano), o Terminal Cidade Florianópolis, a Avenida Hercílio Luz e a Rua Artista Bitencourt (Figura 1); englobando espaços importantes como a Catedral Metropolitana, monumento ao Miramar, Centro Cultural da Marinha, Associação Clube Doze de Agosto e Teatro Álvaro de Carvalho. Como um hub de ações e parceiros dos setores público e privado, o projeto é lançado oficialmente em 15 de setembro de 2015 com apoio do governo, de universidades e instituições ligadas ao comércio, empreendedorismo, audiovisual, turismo, design, tecnologia e infraestrutura.

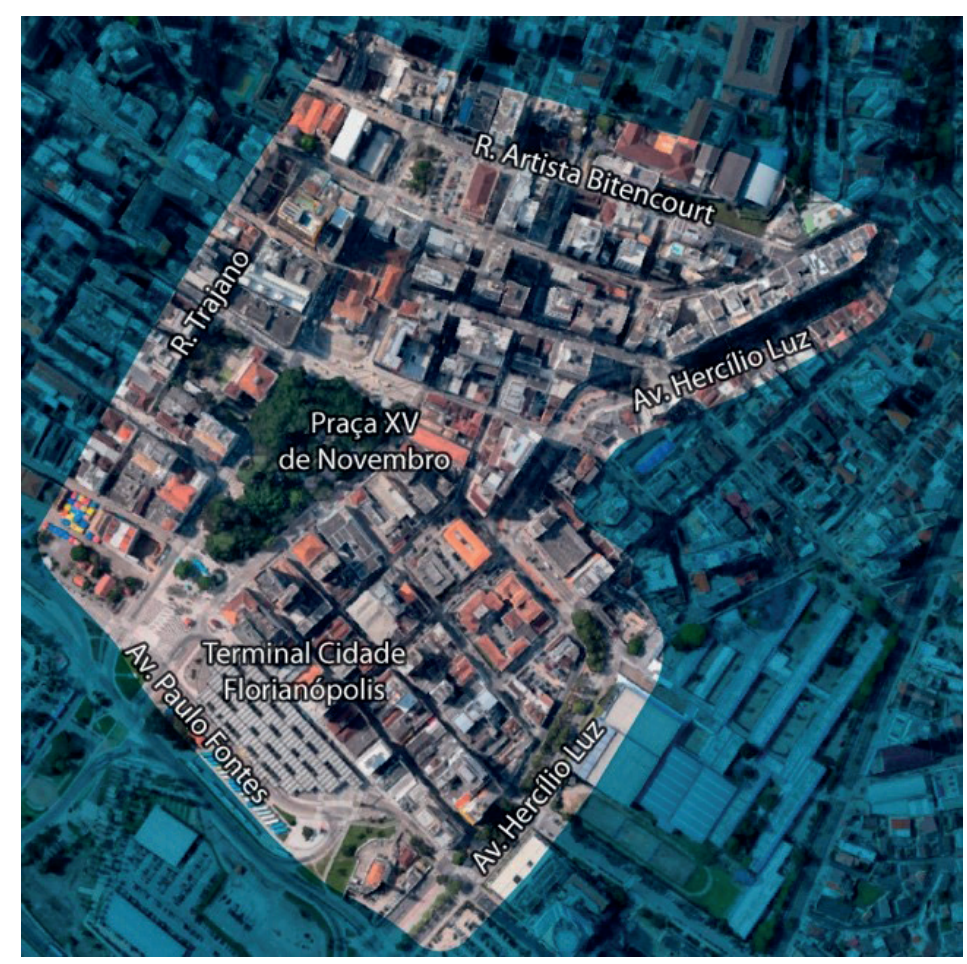

Figura 1: Área do distrito criativo Centro Sapiens.

Fonte: elaborado pelos autores (2017) 
As ações correlatas ao Distrito Criativo Centro Sapiens envolvem desde a meIhoria dos calçamentos, cabeamento elétrico subterrâneo e requalificação urbanística com um todo, até planejamento de estratégias de turismo e ciência, tecnologia e inovação, focadas em tornar o espaço dinâmico e de convivência. Ainda está em tramitação um projeto de lei que prevê a isenção do Imposto Predial e Territorial Urbanas para novas startups que se instalarem no distrito criativo, estimulando a ocupação e investimentos na região. Também é objetivo do projeto a implantação de espaços de inovação como incubadora, aceleradora e centro de design nos próximos anos.

Neste sentido um primeiro passo já foi dado com a criação de uma pré-incubadora, o Cocreation Lab, que tem sede no mezanino do Museu da Escola Catarinense (MESC), uma parceria entre Sapiens Parque, UFSC e UDESC. O prédio histórico do museu foi construído entre 1896 e 1922 para abrigar a Escola Normal Catarinense e desde 2000 é sede do Museu que é administrado pela Universidade do Estado de Santa Catarina. O lançamento do projeto Centro Sapiens aconteceu no museu e em Março de 2016 também recebeu o Circuito de Economia Criativa promovido pelo projeto com a presença de 11 palestrantes com atuação nacional e internacional na área. Na ocasião foi aberto o primeiro edital de pré-incubação do Cocreation Lab, que recebeu a sua primeira turma de empreendedores com ideias voltadas para a Economia Criativa em 21 de Junho de 2016.

O programa de pré-incubação estrutura editais para seleção de ideias semestralmente que devem estar relacionadas aos setores-chave para Florianópolis: tecnologia, turismo, gastronomia, design, arquitetura e artes. Em cada edital pelo menos 10 ideias de negócios são selecionadas, avaliadas em critérios como caráter inovador, potencial de mercado, impacto socioeconômico e ambiental e perfil empreendedor da equipe. Já foram beneficiados 35 projetos com atividades para o desenvolvimento do seu negócio, além do uso do espaço físico estruturado no estilo coworking. São workshops, palestras e mentorias que abordam temas como proposta de valor, modelo de negócio, branding, financeiro, marketing, formalização do negócio; ferramentas como o Business Model Canvas, Mapa da Empatia, criação de pitch; e benefícios de parceiros como pacote Amazon Web Services e curso Empretec/SEBRAE. As atividades são ministradas a partir da rede de parceiros, com profissionais altamente qualificadas nas áreas, com experiência mercadológica e também acadêmica.

o Cocreation Lab e o Museu da Escola Catarinense com um todo tornaram-se o espaço central das atividades do Distrito Criativo Centro Sapiens, proporcionan- 
do a integração das instituições com a comunidade em momentos de discussão sobre a memória da cidade, o espaço urbano, a criatividade e arquitetura. Com esse intuito formou-se um forte grupo de voluntários chamado Movimento Traços Urbanos. Integrando moradores da região, profissionais e organizações de diferentes áreas, o movimento tem realizado diversas ações para fomentar a requalificação dos espaços públicos de Florianópolis, como oficinas sobre arquitetura e sociedade para crianças, intervenções de "varal dos desejos" para o local, prototipagem de pocket places, resgate cultural e arte de rua para idosos, mutirão de limpeza, entre outras ações.

Em congruência com estas ações, o grupo VIA Estação do Conhecimento ${ }^{10}$ (UFSC), entrou para a equipe coordenadora do Distrito Criativo Centro Sapiens no início de 2017, agregando os seus pesquisadores em habitats de inovação e propriedade intelectual, contribuindo para o desenvolvimento das ações gerais do projeto, enquanto articulador da tríplice hélice do conhecimento, como também para a melhoria contínua da metodologia de pré-incubação do Cocreation Lab.

Atualmente o Centro Sapiens e o Cocreation Lab já somam uma rede de mais de 60 parceiros: 15 organizações no comitê gestor, 10 apoiadores institucionais e mais de 35 agentes da pré-incubação entre mentores, ministrantes de atividades e beneficiadores em geral. No Cocreation Lab já beneficiamos até agora 35 projetos selecionados via edital: 11 ligados às áreas de design, arquitetura e artes; 12 gastronomia e turismo; e 12 à área de tecnologia.

Em Julho de 2017, o Centro Sapiens fez parte de uma seleção nacional como 1 de 10 iniciativas de Boas Práticas Urbanística, recebendo menção honrosa"1 no programa "HOJE - Implementando Cidades Sustentáveis". O programa atua como um Fórum Internacional e representa um ciclo de eventos planejados para difundir, debater e criar meios para implementar no Brasil a Nova Agenda Urbana, um compromisso assinado em conferência das Nações Unidas. A agenda traz orientações para promover, por meio da cooperação de todos os setores da sociedade, a urbanização sustentável das cidades nos próximos 20 anos, repensando a forma como construímos, gerenciamos e vivemos em cidades.

\footnotetext{
$10 \quad$ www.via.ufsc.br

11 www.hojecidadessustentaveis.com.br/iniciativas-de-cinco-estados-sao-selecionadas-para-forum-hoje-cidades-sustentaveis/
} 


\section{CONSIDERAÇÕES FINAIS}

As mudanças na economia são irreversíveis, desde o formato de se relacionar com as cidades até na forma de produção não se pode mais imaginar uma volta ao passado com indústrias fumegantes e milhares de operários nas linhas de produção. Neste sentido a economia criativa já se torna uma das referências na chamada indústria 4.0, profissionais nexialistas são cada vez mais exigidos e a criativadade já não é mais diferencial e sim exigência na hora de buscar uma colocação no mercado de trabalho. Ainda deve-se levar em conta que a colocação no mercado de trabalho também mudou. Encontrar empreendedores não é mais uma tarefa tão difícil, as start ups estão em todos os lugares do planeta. Juntando essas duas informações anteriores chega-se a conclusão que o futuro, ou talvez o presente já, é da economia criativa.

As cidades já estão se preparando para isso desde o início do século, no artigo foram apresentados alguns exemplos de sucesso da implantação de projetos voltados para economia criativa e a revitalização/revisitação de lugares em cidades que têm a criatividade e a cultura no seu DNA. Florianópolis é uma delas, e aqui foi apresentado como se está implantando um projeto de referência nos aspectos de revitalização e transformação criativa na cidade. Dos benchmarks encontrados ficou claro que a cidade de Bolonha é a que mais se assemelha em caracterísiticas com Florianópolis desde a formação da população fortemente acadêmica até na baixa valorização da cultura graças a outras formas de turismo exitentes na cidade.

A comparação com Bolonha foi muito auspiciosa e gerou, à partir de uma visita in loco, muitas referências e ideias para a transformação de Florianópolis definitivamente em uma cidade criativa e inteligente. A criação de uma marca forte para a cidade e de um distrito criativo como é o Centro Sapiens com todas suas ações já em funcionamento e as planejadas estão mudando a cara de Florianópolis, já tornando-a benchmark para outras cidades do país e do exterior como São Paulo, Chapecó e Jarágua do Sul no Brasil e Cidade de Praia em Cabo Verde, que já entraram em contato para conhecer e firmar parcerias na implantação de ações similiares.

Finalmente, acredita-se que o principal objetivo da criação do Distrito Criativo Centro Sapiens, que era fortalecer os laços e aproximar o Sapiens Parque das pessoas e dos ideais da cidade de Florianópolis, foi atingido nesses dois anos desde a germinação da ideia até o momento atual e, com as novas ações que se planejam, isso só tende a ampliar. 


\section{REFERÊNCIAS}

ASHEIM, Bjørn; HANSEN, Høgni Kalsø. Knowledge bases, talents, and contexts:

On the usefulness of the creative class approach in Sweden. Economic Geography, v. 85, n. 4, p. 425-442, 2009.

BIANCHINI, Franco; LANDRY, Charles. The creative city. Londres: Demos, 1995. BOP CONSULTING (Reino Unido). British Council (Org.). Guia prático para o mapeamento das indústrias criativas: série economia criativa e cultural/2. Londres: Odai, 2010. 62 p. (Economia Criativa e Cultural).

COMUNE DI BOLOGNA (Itália). Urban Center Bologna. Verso il Piano per I'Innovazione Urbana di Bologna. Bolonha, 2016. 40 p. Disponível em: <http://www. comune.bologna.it/pianoinnovazioneurbana/wp-content/uploads/2017/01/ Verso-il-Piano-per-IInnovazione-Urbana-di-Bologna.pdf> Acesso em: 31 jul 2017. FLORIDA, Richard. The rise of the creative class. Nova York: Basic Books, 2002.

Cities and the creative class. Nova York: Routledge, 2005.

A ascensão da classe criativa. Porto Alegre: LP\&M, 2011.

GASPAR, Jadhi Vincki. MENEGAZZO, Carolina. FIATES, José Eduardo. TEIXEIRA, Clarissa Stefani. GOMEZ, Luiz Salomão Ribas. A Revitalização de Espaços Urbanos: o Case do Centro Sapiens em Florianópolis. In: CONFERÊNCIA ANPROTEC DE EMPREENDEDORISMO E AMBIENTES DE INOVAÇÃO, 26., 2016, Fortaleza, CE. Anais ... Brasília: ANPROTEC, 2016. p 788-809.

GRANDI, Roberto. Bologna City Branding Project. In e-Revista LOGO v.4 n.1 Florianópolis: Incubadora de Periódicos UFSC, 2015

LANDRY, Charles. The creative city: a toolkit for urban innovators. Londres: Comedia and Earthscan Publications, 2000.

LORENTZEN, Anne. Cities in the experience economy. European Planning Studies, v.17, n.6, pp. 829-845, 2009.

QIAN, C. Seize the state, seize the day? Business-government relations in a transition economy. Hong Kong: Hong Kong University of Science and Technology, 2010. REIS, Ana Carla Fonseca. Cidades criativas: análise de um conceito em formação e da pertinência de sua aplicação à cidade de São Paulo. 2011. $297 f$. Tese (Doutorado em Arquitetura e Urbanismo) - Faculdade de Arquitetura e Urbanismo, Universidade de São Paulo, 2011.

TARACHUCKY, Laryssa. Sistematização da aplicação do Brand DNA Process no design de marca de cidades criativas: caso Projeto Rota da Inovação, Florianópolis Laryssa Tarachucky; Florianópolis, SC, 140 p. 2015

TREMBLAY, D. G.; DARCHEN, S. The creative class thesis and the mobility patterns of knowledge workers considering the place of birth: The case of 
Montreal. International Journal of Knowledge-Based Development, v.1, n.3, p.176-203, 2010.

Luiz Salomão Ribas Gomez possui graduação em Desenho Industrial pela Pontifícia Universidade Católica do Paraná, mestrado em Engenharia de Produção pela Universidade Federal de Santa Catarina e doutorado em Engenharia de Produção pela Universidade Federal de Santa Catarina, revalidado na Universidade da Beira Interior (UBI) como Doutorado em Engenharia e Gestão Industrial. Atualmente é professor associado da Universidade Federal de Santa Catarina onde coordena o Laboratório de Orientação da Gênese Organizacional - LOGO e também o projeto Centro Sapiens. Realizou, em 2009, Pos-Doc junto ao UNIDCOM - IADE em Lisboa com o tema 'Brand DNA' e atualmente realiza estágio sênior na Saxion University of Applied Science com o tema 'Inovação, economia criativa e maker spaces'. Tem experiência nas áreas de Design, Inovação e Empreendedorismo Criativo.

Daniele Diniz Warken é especialista em UX Design pela Universidade Federal de Santa Catarina, Bacharela em Design pela mesma instituição. Tem experiência na área de Gestão de Marcas (Branding) e Programação Visual. É pesquisadora vinculada ao LOGO - Laboratório de Orientação da Gênese Organizacional - da UFSC, onde também integrou projetos de extensão enquanto estudante da graduação e da especialização, especialmente voltados para o branding territorial de Florianópolis. Desde 2016 é gestora no projeto Centro Sapiens e na pré-incubadora Cocreation Lab, pesquisando sobre revitalização urbana e empreendedorismo na área de Economia Criativa. Também é CEO na empresa MOOD Lab Design, com atuação em design, branding e interpretação de tendências.

Renato Buchele Rodrigues é Mestre em Administração, Designer Industrial, Especialista em Planejamento, Gestão e Marketing pela Universidade do Vale do Itajaí (2005). É Diretor do Centro de Ciências Sociais Aplicadas - Comunicação, Turismo e Lazer na UNIVALI desde abril de 2014. Atuou por seis anos como coordenador dos cursos de tecnologia em Design e Comunicação desde 2008 na UNIVALI. Faz parte de comissões de projetos de implantação de cursos na área de design, comunicação e inovação na UNIVALI. É avaliador de cursos junto INEP/MEC e Conselho Estadual de Educação CEE/SC. Atua como docente desde

Data de submissão: 01/08/2017. Data de aceite: 13/08/2017. 2002 na graduação e pós-graduação na UNIVALI, UNIASSELVI, ICPG E UNOESC. É doutorando e pesquisador em Turismo e Hotelaria com pesquisas na área de Economia Criativa e Turismo em destinos turísticos consolidados na Europa.

101 
DATA DE SUBMISSÃO: 01/08/2017.

DATA DE ACEITE: 13/08/2017. 